\title{
ADAPTATION OF MUSCLE METABOLISM AND CARDIAC ACTIVITY IN SPECIFIC ENDURANCE TRAINING
}

\author{
Mihaela PUIU1*, Simona BIDIUGAN \\ 1 National Institute for Sport Research, Bucharest, Romania \\ *Corresponding author: mihaela_solcanu@yahoo.com
}

DOI: 10.35189/iphm.icpesk.2019.34

\begin{abstract}
For elite athletes, functional adaptation to the effort specificity is a determining factor for success in competition in many sport branches and events. The influence of endurance capacity on competitive results differs from one sport branch or event to another, based on the effort characteristics required by the competition event (duration, intensity, complexity). A basic principle in developing specific endurance is to understand the immediate and long-term effects of the training on body systems and how they can be measured. From a physiological point of view, the effort specificity can be determined by measuring some physiological parameters and establishing correlations between the values of different parameters. Because the body adaptation to effort produces constant changes in these parameters, the training programmes need to be reorganized and readjusted regularly, depending on the individual physiological response resulting from the adaptive processes. The aim of this study was to determine the individual level of adaptation to the specific effort, based on the correlations between cardiac activity and muscle metabolism. Cardiac activity was assessed by heart rate measurement, and muscle metabolism was determined by measuring the concentration of lactic acid resulting from exercise. The study was conducted on four elite athletes aged between 22 and 26, from different sports: boxing, judo, tennis and athletics. The individual results obtained led to the improvement of the specific endurance training.
\end{abstract}

Keywords: endurance training, muscle metabolism, cardiac activity.

\section{Introduction}

Endurance training induces a variety of physiological responses of the body systems while producing over time a better adaptation of the body to effort, which results in increased performance. Stimulating structural and functional adaptations to improve performance in specific physical tasks remains a major objective of endurance training (McArdle, Katch, \& Katch, 2015, p. 462). A challenge for coaches is to determine the type, duration and intensity of the training programmes and their alternation in the training stages so that they meet the objectives specific to each stage of the training plans. Reaching peak performance in competition is the basis of the training programmes where the alternation of training stimuli with rest is achieved by determining the physiological parameters, which express more objectively the individual level of adaptation to effort. In addition, planning the training variables in accordance with the objectively measured physical response of the body leads to the avoidance of undesirable states of undertraining or overtraining. In order to practically achieve the intended performance capacity, specialists have to answer two main questions:

1. What are the factors that can express the level of individual adaptation to the specific effort as accurately as possible?

2. What changes are required in the training plans according to the individual values of these parameters or the correlations between them?

The best known and most used predictors of endurance capacity in athletes are: maximum aerobic capacity (VO2max), anaerobic threshold (AT) and lactate threshold (LT). Different laboratory or field methods are used to determine these effort indicators. The main parameters measured to determine them are heart rate, blood lactate concentration, $\mathrm{O} 2$ concentration and carbon dioxide in the breathing.

Maximum aerobic capacity or $\mathrm{VO} 2 \mathrm{max}$ is widely considered as the objective measure of endurance capacity. Maximum oxygen consumption (VO2max) is defined as the highest rate of oxygen consumption achieved during maximal exercise (Hoffman, 2014, p. 182). This parameter is very common in measuring the performance capacity of athletes, so that intensities of the training programme are often calculated as a percentage of VO2max. Researchers extensively assessed the effects of endurance training on VO2max and its determinants and four major potential limiting factors for VO2max have been identified: lung diffusion capacity, maximal cardiac output, oxygen-carrying capacity of the blood and skeletal muscle characteristics responsible for the extraction of oxygen at the tissue level of working muscles. The first three factors are classified as "central" factors, and the fourth is termed a "peripheral" factor (Bassett \& Howley, 2000; Warburton, Sheel, \& Mckenzie, 2008, p. 94).

Anaerobic threshold is defined as a physiological point where certain physiological parameters, namely blood lactate concentration ( $\mathrm{La}$ ), minute ventilation (VE), carbon dioxide production (VCO2) and oxygen consumption 
(VO2), have a sudden nonlinear increase as a response to increased exercise intensity (Ignjatović, Hofmann, \& Radovanović, 2008; Wassermann, Whipp, Koyal, \& Beaver, 1973). According to Ignjatović et al. (2008), anaerobic threshold (AT) is a physiological point during exercise, at which muscular lactate production exceeds the rate of lactate oxidation and, as a result, lactate appears in the system and can or cannot be balanced, depending on exercise intensity. Lactate threshold is considered an inflection point that is reached before triggering the progressive increase in lactic acid concentration during incremental efforts. For many athletes, exercise intensity associated with the anaerobic threshold is an important guide for performance capacity. When lactate oxidation is equal to its production, blood lactate level remains stable, even though increases in movement intensity and oxygen consumption may occur (McArdle et al., 2015, p. 162). Training goals depend on the specific metabolic stress of the competition routine. These goals are either to achieve higher exercise intensity (e.g., a higher running speed) at the same lactic acid concentration or to increase the amount of time the athlete can maintain the value of lactic acid concentration associated with the anaerobic threshold, or both. Daniels (2013, p. 53) believes that a very well-trained elite athlete is able to run at the speed of the anaerobic threshold, maintaining a constant production of lactic acid for about 60 minutes. Numerous studies have shown that improving anaerobic endurance capacity is accompanied by increased muscle capacity to metabolise lactic acid (Hargreaves \& Spriet, 2006, p. 202; Dubouchaud, Butterfield, Wolfel, Bergman, \& Brooks, 2000). Thus, an objective of athlete training is to produce lower lactate concentration at the same exercise intensity.

Lactic acid is a metabolic product of anaerobic glycolysis, whose blood concentration increases exponentially with increasing exercise intensity, due to a decrease in the ability to produce energy through aerobic mechanisms. As a result, blood lactate levels are an important parameter in determining exercise intensity in training and competitions. Some specialists consider that lactate variables, such as lactate threshold and the onset of blood or plasma lactate accumulation, are often better predictors of endurance performance than maximal $\mathrm{O} 2$ uptake (Hargreaves \& Spriet, 2006, p. 41). Determination of lactic acid levels in high intensity training and their correlation with the levels produced in competition is an important indicator of exercise intensity, especially in the training sessions aimed at modelling competitive stress. In high-intensity sport disciplines, lactic acid concentration can reach very high levels, for instance $20-21 \mathrm{mmol} / \mathrm{L}$ in $400-\mathrm{m}$ and $800-\mathrm{m}$ races (Lacour, Bouvat, \& Barthélémy, 1990). For effective adaptation, the training effort should produce high-lactate levels in these athletes.

Heart rate (HR). The cardiovascular system is responsible for delivering oxygen and nutrients to active organs and muscles and removing the waste products of metabolism (Hoffman, 2014, p. 55). Depending on the specificity of effort, various short- or long-term adaptive responses of cardiovascular indicators (cardiac volume, heart rate, blood pressure, peripheral vascularisation) appear. Overall, cardiovascular function improves cardiovascular adaptations at central and peripheral levels. Central cardiovascular adaptation occurs in the heart, which increases its ability to deliver oxygen. Peripheral cardiovascular adaptation occurs in the vasculature or muscles and contributes to an increased ability to extract oxygen (Plowman \& Smith, 2014, p. 395). Heart rate is a particularly sensitive indicator of the effort characteristics, intensity and volume. As a result, heart rate provides accurate information about the level of cardiovascular adaptation to different work intensities and amounts of effort, recovery or fatigue and, consequently, is an index of the performance capacity of athletes (Sarmiento, GarcíaManso, Martín-González, Vaamonde, \& Calderón, 2013). For assessing the level of cardiovascular adaptation to exercise, heart rate values are measured at specific moments of training: under basal conditions in clinostatism and orthostatism, maximum or average HR values during exercise, as well as HR values at different time intervals after exercise. In practice, heart rate monitoring is a simple and common method for measuring effort (its duration and type, but also the duration and type of recovery). In well-trained athletes, after long-term workouts, there are relatively stable major adaptive changes at cardiac level, such as resting bradycardia, low systolic volume at rest, low heart rate at rest and increased effort, increased cardiac output and ventricular wall hypertrophy (Drăgan, 1989, p. 38). Like VO2max, heart rate is an indicator of exercise intensity, and many specialists recommend heart rate values for effort as a percentage of maximum heart rate. Endurance exercise reduces the metabolic load on the resting heart at any submaximal exercise intensity, increasing stroke volume and decreasing heart rate. The result is a more efficient pressure-time relationship (Aubert, Seps, \& Beckers, 2003). Heart rate values measured at specific moments and correlated with lactic acid concentration indicate the adaptation of athletes to the specific effort and provide important information for the efficient training planning. 


\section{Purpose of research}

The purpose of the research was to determine muscle metabolism and cardiorespiratory stress induced by a training stimulus to improve specific endurance.

\section{Objectives of research}

1. Determining the individual level of metabolic and cardiovascular adaptation to specific effort.

2. Optimising individual training plans for specific effort.

3. Defining optimal training parameters (volume and intensity) for individual training plans.

\section{Problem statement}

In this study, we aimed to determine the effect of a training stimulus on cardiovascular activity and muscle metabolism in four sport disciplines (boxing, judo, tennis and athletics). This was achieved by measuring the values of two parameters, heart rate (HR) and lactic acid concentration (La) in capillary blood. Furthermore, we intended to point out whether the physiological response of the athlete's body to the training task was in accordance with the specific goals proposed by coaches for that training session. Thus, heart rate values and lactic acid concentration were related to the values established by the Biochemistry Laboratory of the National Institute for Sport Research (INCS) for the classification of efforts. This classification includes six effort zones shown in Table 1.

Table 1. Effort zones

\begin{tabular}{llcc}
\hline $\begin{array}{c}\text { Item } \\
\text { no. }\end{array}$ & \multicolumn{1}{c}{ Effort zones } & $\begin{array}{c}\text { Heart rate } \\
(\mathrm{bpm})\end{array}$ & $\begin{array}{c}\text { Lactate concentration } \\
(\mathrm{mmol} / \mathrm{L})\end{array}$ \\
\hline 1 & Oxygen zone $\left(\mathrm{O}_{2}\right)$ & $130+/-5$ & $0-1.5$ \\
2 & Stable oxygen zone $\left(\mathrm{SO}_{2}\right)$ & $150+/-10$ & $2-3.5$ \\
3 & Relative oxygen zone $(\mathrm{RO})$ & $160+/-10$ & $3-5$ \\
4 & Lactate - oxygen zone $\left(\mathrm{O}_{2} \mathrm{LA} 2\right)$ or maximum & $170+/-5$ & $5-12$ \\
& oxygen uptake zone & $180+/-5$ & $12-18$ \\
5 & Lactate - oxygen zone 1 $\left(\mathrm{O}_{2} \mathrm{LA} 1\right)$ & $190+/-5$ & 18 \\
6 & Lactate - oxygen zone $\left(\mathrm{LA}_{2}\right)$ & & \\
\hline
\end{tabular}

\section{Material and Methods}

The research method used was the case study.

\section{Subjects of research}

The study included four elite athletes from boxing (S1), judo (S2), tennis (S3) and athletics (S4), aged between 22 and 26 years. The boxing athletes were male, and the other three subjects were female.

\section{Measured parameters}

The effort characteristics were determined by measuring heart rate and 15 biochemical parameters of the acidbase balance, of which lactic acid concentration was the most relevant for the study. Biochemical parameters were measured from capillary blood under basal conditions, 2.5 minutes after the end of the effort. Heart rate was measured throughout the exercise, and maximum heart rate was critical for this study.

\section{Tools used}

Polar Team 2 - is a specially designed application to measure heart rate during the training effort, simultaneously for several athletes.

To assess the acid-base balance, an ABL835 analyser was used. This instrument measures 15 biochemical parameters: haemoglobin $(\mathrm{Hb})$, blood $\mathrm{pH}(\mathrm{pH})$, blood oxygen $\left(\mathrm{pO}_{2}\right)$ and carbon dioxide pressure $\left(\mathrm{pCO}_{2}\right)$, current plasma bicarbonate $\left(\mathrm{HCO}_{3}\right)$ and standard values (SBC), oxygen-saturated haemoglobin (SAT), base excess (BE), standard base excess (SBE), metabolic cost $(\mathrm{R})$, lactate $(\mathrm{La})$, sodium $(\mathrm{Na})$, potassium $(\mathrm{K})$ and chlorine $(\mathrm{Cl})$ ions. 


\section{The effort provided by subjects}

Subject no. 1. The training effort involved the participation of a sparring opponent of the same category and level of performance. The exercise lasted three rounds of 3 minutes each, with 1 minute of recovery between rounds.

Subject no. 2 performed a competition-specific effort (Randori) with an opponent of the same category and level of performance. The work schedule consisted of four series, each series having four rounds of effort, with an increase in duration of $10 \mathrm{sec}, 20 \mathrm{sec}, 30 \mathrm{sec}$ and $1 \mathrm{~min}$, together with passive recovery between rounds, with duration of $5 \mathrm{sec}, 10 \mathrm{sec}$ and $15 \mathrm{sec}$. The rest time was 2 minutes between series. The four series were executed twice, with a 4-minute recovery time between them.

Subject no. 3 performed a nonspecific effort, the Cooper Test, for the assessment of endurance capacity. The athlete had to run for 12 minutes over the distance of $2200 \mathrm{~m}$.

Subject no. 4, a middle-distance race athlete specialised in 400-m events, performed 200-m runs for 5 times, with in-between repetition breaks of about 10 sec each.

\section{Results and Discussion}

The measurements of biochemical parameters under basal conditions are shown in Table 2, and the values measured 2.5 minutes after the end of the effort are shown in Table 3. Maximum heart rate measured during exercise is shown in Table 3. Since the study method was the case study, both the interpretation and discussion of the results were made individually.

Table 2. Values of the parameters measured under basal conditions

\begin{tabular}{lcccccc}
\hline Item no. & \multirow{2}{*}{ Parameters } & \multirow{2}{*}{ Measurement unit } & \multicolumn{5}{c}{ Subjects } \\
\cline { 4 - 7 } & & $\mathrm{S} 1$ & $\mathrm{~S} 2$ & $\mathrm{~S} 3$ & $\mathrm{~S} 4$ \\
\hline 1. & $\mathrm{Hb}$ & - & 15 & 14.5 & 17.7 & 13.8 \\
2. & $\mathrm{pH}$ & $\mathrm{gH}$ & 7.44 & 7.38 & 7.39 & 7.43 \\
3. & $\mathrm{pCO}_{2}$ & $\mathrm{mmHg}$ & 44 & 42.5 & 40.4 & 34 \\
4. & $\mathrm{pO}_{2}$ & $\mathrm{mmHg}$ & 89 & 63.1 & 64 & 84 \\
5. & $\mathrm{HCO}_{3}$ & $\mathrm{mmol} / \mathrm{L}$ & 21 & 24 & 24.7 & 22 \\
6. & $\mathrm{BE}$ & $\mathrm{mmol} / \mathrm{L}$ & -2 & -1 & 0 & -1 \\
7. & $\mathrm{SBE}$ & $\mathrm{mmol} / \mathrm{L}$ & -2 & 0 & 0 & -1 \\
8. & $\mathrm{SAT}$ & $\mathrm{mmol} / \mathrm{L}$ & 99 & 92 & 92 & 96 \\
9. & $\mathrm{SBC}$ & $\mathrm{mmol} / \mathrm{L}$ & 22 & 24 & 24 & 24 \\
10. & $\mathrm{La}$ & $\mathrm{mmol} / \mathrm{L}$ & 2 & 1.2 & 0.5 & 1.2 \\
11. & $\mathrm{R}$ & $\mathrm{mmol} / \mathrm{L}$ & 1.04 & 1 & 0.97 & 1.09 \\
12. & $\mathrm{Na}$ & $\mathrm{mmol} / \mathrm{L}$ & 146 & 147 & 143 & 145 \\
13. & $\mathrm{~K}$ & $\mathrm{mmol} / \mathrm{L}$ & 4.25 & 4.1 & 4.17 & 4.17 \\
14. & $\mathrm{Ca}$ & $\mathrm{mg} / \mathrm{dl}$ & 4.2 & 4.55 & 4.14 & 4.34 \\
15. & $\mathrm{Cl}$ & $\mathrm{mmol} / \mathrm{L}$ & 113 & 114 & 110 & 112 \\
\hline
\end{tabular}

Table 3. Values of the parameters measured after effort

\begin{tabular}{lcccccc}
\hline Item no. & \multirow{2}{*}{ Parameters } & \multirow{2}{*}{ Measurement unit } & \multicolumn{4}{c}{ Subjects } \\
\cline { 4 - 7 } & & & $\mathrm{S} 1$ & $\mathrm{~S} 2$ & $\mathrm{~S} 3$ & $\mathrm{~S} 4$ \\
\hline 1. & $\mathrm{HR}$ & $\mathrm{bpm}$ & 175 & 187 & 188 & 180 \\
2. & $\mathrm{Hb}$ & $\mathrm{g} / \mathrm{dl}$ & 15 & 15 & 15.7 & 15 \\
3. & $\mathrm{pH}$ & - & 7.41 & 7.29 & 7.32 & 7.37 \\
4. & $\mathrm{pCO}_{2}$ & $\mathrm{mmHg}$ & 30 & 32.4 & 35.5 & 34 \\
5. & $\mathrm{pO}_{2}$ & $\mathrm{mmHg}$ & 108 & 83.3 & 82 & 78 \\
6. & $\mathrm{HCO}_{3}$ & $\mathrm{mmol} / \mathrm{L}$ & 19 & 15 & 18.2 & 19 \\
7. & $\mathrm{BE}$ & $\mathrm{mmol} / \mathrm{L}$ & -4 & -10 & -7.3 & -5 \\
8. & $\mathrm{SBE}$ & $\mathrm{mmol} / \mathrm{L}$ & -5 & -10 & -8 & -5 \\
9. & $\mathrm{SAT}$ & $\mathrm{mmol} / \mathrm{L}$ & 98 & 95 & 95.1 & 95 \\
10. & $\mathrm{SBC}$ & $\mathrm{mmol} / \mathrm{L}$ & 21 & 16 & 18.6 & 21
\end{tabular}


International Proceedings of Human Motricity/ICPESK 2019

Supplementary Issue of Discobolul - Physical Education, Sport and Kinetotherapy Journal, 2019

\begin{tabular}{lcccccc}
11. & $\mathrm{La}$ & $\mathrm{mmol} / \mathrm{L}$ & 3.6 & 8.3 & 6.17 & 4.36 \\
12. & $\mathrm{R}$ & $\mathrm{mmol} / \mathrm{L}$ & 1.05 & 1.06 & 1.02 & 1.11 \\
13. & $\mathrm{Na}$ & $\mathrm{mmol} / \mathrm{L}$ & 143 & 147 & 145 & 144 \\
14. & $\mathrm{~K}$ & $\mathrm{mmol} / \mathrm{L}$ & 5.6 & 5 & 5.67 & 5.2 \\
15. & $\mathrm{Ca}$ & $\mathrm{mg} / \mathrm{dl}$ & 3.98 & 4.32 & 4.24 & 4.2 \\
16. & $\mathrm{Cl}$ & $\mathrm{mmol} / \mathrm{L}$ & 109 & 110 & 115 & 113 \\
\hline
\end{tabular}

Subject no. 1 achieved a maximum HR value of 175 beats per minute (bpm) and a lactic acid concentration of $3.6 \mathrm{~mm} / \mathrm{L}$ (Figure 1). It can be noticed that the physiological response of the body indicates that the workload intensity was in zone 3, relative oxygen (RO) being characterised by HR values of $160+/-10$ and lactate concentration between 3-5 mmol/L. Moreover, we can observe a slightly increased HR $=175 \mathrm{bpm}$ compared to $170 \mathrm{bpm}$, the maximum value for that effort zone. The relative oxygen (RO) zone includes the efforts at which the heart rate has values of $160+/-10 \mathrm{bpm}$. This aspect demonstrates an inadequate level of cardiorespiratory training. In order to correct this deficiency, the training in both zones (stable oxygen and relative oxygen) was also recommended. Although the athlete achieved an effort similar to the competition effort, in terms of the physiological response, the training stimulus did not cause similar reactions. In the measurements made by INCS biochemists at boxing competitions, lactate concentration was between 12 and $20 \mathrm{mmol} / \mathrm{L}$, and HR was higher than $180 \mathrm{bpm}$. As a result of these measurements, we believe that the competitive effort in high-performance boxing is in the oxygen - lactate 1 (O2 LA1) and lactate - oxygen (LA O2) effort zones. Thus, the effort in the specific training should produce physiological reactions characteristic to this zone. In addition, highly efficient aerobic mechanisms are required not only during the specific effort, but also in the recovery phase to decrease high-lactate concentration.

Subject no. 2. The judo athlete reached a maximum heart rate value of $187 \mathrm{bpm}$ and a blood lactate concentration of $8.3 \mathrm{mmol} / \mathrm{L}$ (Figure 1). These values indicate that exercise intensity was in zone 4, Oxygen Lactate Zone 2 (O2 LA2). It should be mentioned that optimal heart rate intervals and lactate concentration for this effort zone are $170+/-5 \mathrm{bpm}$ and 5 to $12 \mathrm{mmol} / \mathrm{L}$.

Subject no. 3. As with the judo athlete, the effort of the tennis player was placed in Oxygen Lactate Zone 2 (O2 LA2). The subject reached a maximum heart rate value of $188 \mathrm{bpm}$ and a blood lactate concentration of 9.7 mmol/L (Figure 1). Both athletes (no. 2 and no. 3) reached a too high heart rate exceeding the effort zone where the work intensity decreased.

Subject no. 4. The athlete obtained values of the measured parameters in accordance with the specific values of the relative oxygen zone (RO), with a maximum heart rate of $180 \mathrm{bpm}$ and a lactic acid concentration of 4.36 $\mathrm{mmol} / \mathrm{L}$ (Figure 1). It can be noticed that the recorded heart rate is higher than the upper limit of the relative oxygen effort zone. Similar to the other three subjects, it can be observed an insufficient cardiovascular adaptation compared to muscle metabolism, which produces relatively low lactic acid levels.

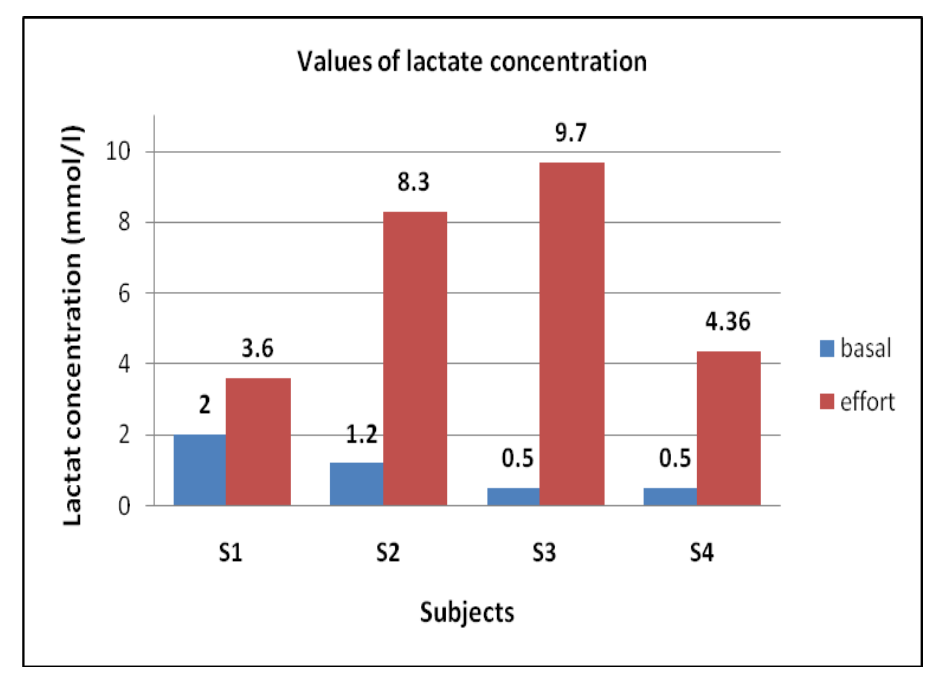

Figure 1. Values of lactate concentration 
From this study, we found out that all four athletes showed insufficient cardiovascular adaptation to the training stimulus in relation to muscle metabolic activity. To correct this deficiency, long-term effort with intensity in the stable oxygen zone $\left(\mathrm{SO}_{2}\right)$ and relative oxygen zone (RO) are recommended. This type of effort provides cardiorespiratory efficiency by increasing cardiac output and peripheral vascularisation. This ensures an increase in the level of muscle oxygenation, which improves lactic acid metabolism, and thus increases the quality of recovery processes.

\section{Conclusion}

Each sport discipline has some particularities in terms of physiological demands. Also, in any sport discipline, especially opposition sports, competition may produce different demands, depending on objectives, the performance level of the opponents and the specific rules (which may or may not allow different interruptions of the effort or changes of athletes during the competition). Each coach can produce an adequate increase in the endurance capacity of athletes by measuring different parameters that accurately characterise the effort. Laboratory tests are well known and useful, but these methods assess at a given time the level of adaptation to the effort in relation to the training stage. In day-to-day practice, however, coaches and athletes need to know if the training stimulus (volume, intensity) is in accordance with the proposed goal, the level of adaptation of the athlete to the effort and the specificity of the competition effort.

An objective and efficient training method is to measure heart rate and lactate concentration, which can provide information about: the level of adaptation and the amount of cardiovascular stress during the effort, the type of metabolism involved in producing the energy needed to support the effort, the level of athlete recovery, the balance between cardiovascular activity and muscle metabolism. We can say that this method immediately assesses the effects of training in real time, which allows making quick corrections in the training plans and avoiding undesirable situations of overtraining or undertraining.

\section{References}

Aubert, A. E., Seps, B., \& Beckers, F. (2003). Heart rate variability in athletes. Sports Medicine, 33(12), 889-919. https://doi.org/10.2165/00007256-200333120-00003

Bassett, D. R., \& Howley, E. T. (2000). Limiting factors for maximum oxygen uptake and determinants of endurance performance. Medicine \& Science in Sports \& Exercise, 32(1), 70-84. http://dx.doi.org/10.1097/00005768-200001000-00012

Daniels, J. (2013). Daniel's running formula ( $3^{\text {rd }}$ ed.). Human Kinetics.

Drăgan, I. (1989). Practica medicinii sportive [The practice of sport medicine]. București: Editura Medicală.

Dubouchaud, H., Butterfield, G. E., Wolfel, E. E., Bergman, B. C. F., \& Brooks, G. A. (2000). Endurance training, expression and physiology of LDH, MCT1 and MCT4 in human skeletal muscle. American Journal of $\begin{array}{lllll}\text { Physiology, } & \text { Endocrinology }\end{array}$ https://doi.org/10.1152/ajpendo.2000.278.4.E571

Hargreaves, M., \& Spriet, L. L. (2006). Exercise metabolism ( $2^{\text {nd }}$ ed.). Human Kinetics.

Hoffman, J. (2014). Physiological aspects of sport training and performance $\left(2^{\text {nd }}\right.$ ed.). Human Kinetics.

Ignjatović, A., Hofmann, P., \& Radovanović, D. (2008). Non-invasive determination of the anaerobic threshold based on the heart rate deflection point. Facta Universitatis, Series: Physical Education and Sport, 6(1), 1-10. Retrieved from http://facta.junis.ni.ac.rs/pe/pe200801/pe200801-01.pdf

Lacour, J. R., Bouvat, E., \& Barthélémy, J. C. (1990). Post-competition blood lactate concentrations as indicators of anaerobic energy expenditure during 400-m and 800-m races. European Journal of Applied Physiology and Occupational Physiology, 61(3-4), 172-176. https://doi.org/10.1007/BF00357594

McArdle, D. W, Katch, F. I., \& Katch, V. L. (2015). Exercise physiology: Nutrition, energy and human performance ( $8^{\text {th }}$ ed.). Philadelphia: Wolters Kluwer Health/ Lippincott Williams \& Wilkins.

Plowman, S. A., \& Smith, D. L. (2014). Exercise physiology for health, fitness and performance (4 ${ }^{\text {th }}$ ed.). Lippincott Williams \&Wilkins.

Sarmiento, S., García-Manso, J. M., Martín-González, J. M., Vaamonde, D., \& Calderón, J. (2013). Heart rate variability during high-intensity exercise. Journal of Systems Science and Complexity, 26(1), 104-116. https://doi.org/10.1007/s11424-013-2287-y 
Warburton, D. E. R., Sheel, A. W., \& Mckenzie, D. C. (2008). Cardiorespiratory adaptations to training. In M. P. Schwellnus (Ed.), Olympic textbook of medicine in sport (Vol. XIV, pp. 93-110). John Wiley \& Sons, Ltd.

Wassermann, K., Whipp, B. J., Koyal, S. N., \& Beaver, W. L. (1973). Anaerobic threshold and respiratory gas exchange during exercise. Journal of Applied Physiology, 35(2). 236-239. https://doi.org/10.1152/jappl.1973.35.2.236 